\title{
Lab Notes
}

\section{An Assessment of Using Audio and Videotapes in a Lab Class- room: The Soochow Experience by Chi-Fang (Cynthia) Yu Soochow University (Taiwan)}

\begin{abstract}
\end{abstract}
Introduction

Traditional ESL instructors have assumed that the language laboratory reflects the theoretical orientation of audio-lingual theory, a structure-based approach which views foreign language learning as a process of mechanical habit formation. (Richards and Rodgers 1986, 51) Dialogues and drills form the basics of classroom practice. In this sense, "[t]he 'reigning technology,' the reel-to-reel or audio cassette-based language laboratory, support[s] the objectives of the behaviorist ALM [audio-lingual method] school and developed in tandem with 
this movement." (Lyman-Hager 1992, 7) It provides the perfect opportunity for drill work with basic structures. However, through this kind of training, students are frequently unable to understand the native speaker's response, because, unlike natural language learners, they lack the contextualization needed for rapid comprehension and effective long-term learning. (Krashen and Terrell 1988) "Along with the growing realization of the importance of language learning there has come a pronounced dissatisfaction with the former means (drill and practice) used to achieve linguistic competence." (Lyman-Hager 1992, 7)

Inasmuch as video is capable of delivering messages via both sight and sound, "[v]ideotapes and videodiscs represent a significant advance in the materials available for language students." (Cline 1991, 26) The immediacy and impact of video's visual and auditory reinforcement far surpasses the all-aural effect of audio. As Junetta Gillespie (1991, 9 - 10) points out, according to the experimental findings of Mehrabian (1972), approximately 55\% of the attitudinal aspect of human communication is based on facial expression, with another $38 \%$ being based on paralinguistic features, leaving $8 \%$ to lexical and grammatical features of communication.

Mary Ann Lyman-Hager $(1992,9)$ also observes, "No one who has passed the Piagetian 'age of reason,' say twelve years of age, is content for long to speak at the disconnected, uncontextualized sentence level, especially in the absence of visual stimuli. It is totally unnatural and downright perverse for us to require this of students.... If the new technologies can offer this, who are we pedagogues to stand in the way?" Curtis Swanson $(1992,44)$ further reiterates, "The language laboratory must abandon the primacy of the audiotape in favor of a combination of video and audio. Today's students are visually oriented. Their attention wanders if they are not stimulated both visually and aurally. Teachers also recognize the importance of the visual component in processing language and understanding the cultural context of language.... The costs of both hardware and programs will be much greater than for audio capability alone; however, the energy and excitement of such multimedia presentations can revitalize the language laboratory environment."

Instructors who have actually integrated video as part of their lab program have achieved gratifying results. Tracy David Terrell (1989) claims that with video technology being readily available and relatively inexpensive, second language learners can be exposed to a wider range of listening contexts. To summarize his paper, he concludes, "Although video 
courses...require a large amount of advance preparation time, they are, for students without experience living in the target culture, the only way to move students from an intermediate level to an advanced level in listening skills." (23)

Paul Aoki (1992, 4-5) also reports, "This approach of expecting students to deal with French spoken at a normal rate and the native speakers interacting with each other in their native environment provided our students with the aurally represented language and customs, paralinguistic information such as gestures and body language.... [T] he students internalized many paralinguistic signals simply by watching the video. When asked to speak and converse in class, the students automatically incorporated the gestures and body language."

Since there is substantial evidence to show that the use of videotapes is needed to achieve maximum success in language teaching, the traditional audiotapes for the Lab Programs I \& II at Soochow University have been replaced with the Family Album, USA videotapes, published by Maxwell Macmillan International Publishing Group. This video series presents continuous episodes depicting stories about a typical American family living in New York.

\section{Survey Of The Students}

Introduction

Unlike the system in many other countries, the lab program at universities in Taiwan is a self-contained course. At Soochow University, all students are required to take this course for two years to improve their English listening and speaking abilities. They receive credit for the course. In order to find out about the students' attitudes towards using solely the audio medium or the video medium and their comparison of the two media for language learning in the lab classroom, the author conducted a survey of this student population.

Subjects A total of 2,974 sophomores who completed the Lab Courses I \& II using audiotapes and videotapes respectively were surveyed in April 1993-eight months after the videotapes were put to use.

Survey The printed survey was developed in Chinese, consisting of 2 sections. Part I contained 15 questions dealing with the students' attitude towards using video and audio in the lab. Students were asked to compare the use of video and audio in four major areas: preparing for classes and exams, in-class interaction, teaching techniques, and the effectiveness for language training. For each question students were told to select 
the answer that most suitably described their own view or belief. The English translation of the survey questions is presented below. In Part II the students were asked to compare their experiences in using audio and video according to the categories given and then write their responses. This gave students a chance to express their individual opinions on the issues.

In this Note only the results of the questions addressing student modality preference will be discussed.

\section{Survey of Students} (English Version)

Introduction
This survey is to find out about your experience in the Lab Courses I \& II using audiotapes and videotapes respectively. The results will be used to determine future curriculum to further enhance students' listening and speaking abilities. It is sincerely hoped that you will answer the questions carefully according to your own personal experience.

Part I: Instruction: For each question, select the answer that most suitably describes your own situation.

1. I have to spend more time and effort preparing and reviewing lessons when using
a. videotapes
b. audiotapes
c. there is no difference

2. I concentrate better in class when using
a. videotapes
b. audiotapes
c. there is no difference

3. I have more chances to interact with the teacher and other students when using
a. videotapes
b. audiotapes
c. there is no difference

4. I have more chance for repeated practice in class when using .
a. videotapes
b. audiotapes
c. there is no difference

5. I have to spend more time and effort preparing for exams when using
a. videotapes
b. audiotapes
c. there is no difference

6. It's easier for me to understand and handle the content of the lessons when using
a. videotapes
b. audiotapes
c. there is no difference

7. There is a better variety of classroom activities when using
a. videotapes
b. audiotapes
c. there is no difference 
8. The teacher has a better understanding of the students' abilities so as to adjust the pace to suit the need of the students when using
a. videotapes
b. audiotapes
c. there is no difference

9. There is more flexibility in the teacher's lesson planning when using
a. videotapes
b. audiotapes
c. there is no difference

10. The teacher is more able to operate the machines when using
a. videotapes
b. audiotapes
c. there is no difference

11. I can better understand the cultural aspects of the target language (American English) when using
a. videotapes
b. audiotapes
c. there is no difference

12. It is more convenient (easier) for me to prepare or review lessons at home when using
a. videotapes
b. audiotapes
c. there is no difference

13. Generally speaking, using is better in helping me improve my listening ability.
a. videotapes
b. audiotapes
c. there is no difference

14. Generally speaking, using is better in helping me improve my speaking ability.
a. videotapes
b. audiotapes
c. there is no difference

15. If I had the choice, I would like the teacher to use
a. videotapes only
b. audiotapes only
c. both equally
d. videotapes more
e. audiotapes more

Part II: Instructions: If there is anything you need to add to the above, please state your experience according to the categories given below.

Item

When I took:

\section{Lab Course I Lab Course II}

1. Use of machines

2. Level of difficulty of the materials used 
3. Pre-class preparation at home

4. Classroom environment

5. Teacher's method of teaching

6. Teacher-student interaction

7. Teacher's evaluation of students

8. Opportunity to use English outside the classroom

9. Content of exams

10. Frequency of use of media center

11. Others

Results For the quantitative analysis of this data, the SPSS/PC+ Data Analysis

Students' general responses towards using audio/video program was used to provide descriptive statistics.

Students showed a significant preference toward using videotapes for training their listening and interactive skills for the lab course. For 12 out of the 15 questions asked, students answered positively in regards to using video and the differentials between the students' choosing video and the students' choosing audio is substantial.

A closer look at the students' answers to the questions addressing student modality preference will provide us a better picture of how they viewed the media used.

Items showing high preference for video
- $90.5 \%$ of the students indicated that they could better understand the cultural aspects of the target language when videotapes were used; $2.5 \%$ of the students felt audio was better in this regard with the remaining saying there was no difference between the two.

- $74 \%$ of the students said that it was easier for them to understand and handle the content of the lessons when using videotapes; $11.3 \%$ favored audio; and $14.1 \%$ thought there was no difference.

- $70.5 \%$ of the students claimed that they concentrated better in class when using videotapes; $16.9 \%$ thought they did better with audio; and $10.8 \%$ thought it didn't matter.

- $58.7 \%$ of the students indicated that using videotapes was better in helping them improve their speaking abilities; $13.6 \%$ thought audio; and $27 \%$ thought there was no difference. 
Items showing moderate preference for video

Items showing no difference

Items showing preference for audio

Choosing between the two media

Conclusion

The data suggest that a majority of students in the ESL program at Soochow University would prefer to use video if they had a choice. Most students would prefer to have video used for the lab course because they are accustomed to learning things through visual information processing. They also think using video better enhances the acquisition of both listening and speaking abilities. The experiment demonstrated to some degree the credibility of this view. Further research along this line needs to be done with different groups of language learn- 
ers or with different core text materials to corroborate the present findings.

However, some students feel that visual information interferes with their ability to understand verbal information. Several theorists have recognized this tendency; e.g., Gunter (1980). They find that information processing capacities are taxed by adding visual information. In Basil's study $(1992,1)$, he also indicates "Auditory information, however, was better remembered when viewers were focused on the audio channel. Auditory information and auditory-based messages appear to demand greater resources than visual information and visual-based messages."

Levin, Divine-Hawkins, Kerst, and Guttman (1974) observed that for many learners there was no preferred modality presentation (aural or visual); i.e., learning via one mode or the other did not lead to a significant difference in outcome. Approximately 25 per cent of the learners, however, performed better when using a particular mode for instruction. Lepke (1977) found that the French students at a junior college in Texas not only performed better, but also there was a substantial increase in enrollment in language courses when they could choose their preferred mode of presentation.

In brief, teachers and others studying second language acquisition can benefit from knowing more about how their students learn, and this study, in particular, aims at providing teachers in Taiwan with a better understanding of the use of AV media for instruction. It is hoped that the information presented here about student preferences can help university level EFL teachers to assist their students in learning English more enjoyably and effectively.

\section{Acknowledgements}

I gratefully acknowledge the assistance of the teachers and the students as well as the staff members of Soochow University, Language Center, who helped me to conduct surveys successfully on a large school-wide scale. Without their help, this study would not have been possible.

References Aoki, P. (1992). Using Technology in Future Foreign Language Education. Designing the Learning Center of the Future, Language Laboratories: Today and Tomorrow. Instructional Design International, Inc. $3-8$.

Basil, M.D. (1992). Attention to and Memory for Audio and Video Information in Television Scenes, paper presented at the 42nd Annual Meeting of the International Communication Association. 
Cline, William. (1991). Interactive Video: One Monitor or Two? IALL Journal of Language Learning Technologies, Vol. 24, No. 3, Fall 1991. 25 - 35.

Gillespie, Junetta. (1991). Videodiscs as Databases. IALL Journal of Language Learning Technologies, Vol. 24, No. 3, Fall 1991. 9 - 14 .

Gunter, B. (1980). Remembering Televised News: Effects of Visual Format on Information-Gain. Journal of Educational Television and Other Media, 6, Spring 1980. 8-11.

Krashen, Stephen P., \& T. D. Terrell. (1988). Second Language Acquisition Theory. The Natural Approach: Language Acquisition in the Classroom. Prentice Hall International English Language Teaching. $23-38$.

Lepke, H. (1977). Discovering Student Learning Styles Through Cognitive Style Mapping. Personalizing Foreign Language Instruction: Learning Styles and Teacher Options, ed. R. Shulz. National Textbook Co., Skokie, IL.

Levin, J., P. Divine-Hawkins, S. Kerst, and J. Guttman. (1974). Individual Differences in Learning from Pictures and Words: the Development and Application of an Instrument. Journal of Educational Psychology, 66, No. 3, June 1974. 296 - 303.

Lyman-Hager, Mary Ann. (1992). Toward a New Pedagogy. IALL Journal of Language Learning Technologies, Vol. 25, No. 2, Spring 1992. 7 - 13.

Richards, Jack C., \& Theodore S. Rodgers (1986). The Audiolingual Method, Communicative Language Teaching. Approaches and Methods in Language Teaching: A Description and Analysis. Cambridge Teaching Library. $44-86$.

Swanson, C. (1992). Technological Advances in the Language Laboratory. Designing the Learning Center of the Future, Language Laboratories: Today and Tomorrow. Instructional Design International, Inc. 43 - 44.

Terrell, Tracy David. (1989). Comprehensible Input for Intermediate Foreign Language Students Via Video, reprinted in IALL Journal of Language Learning Technologies, Vol. 26, No. 2, Spring 1993. 17 - 23.

Chi-Fang (Cynthia) Yu is the Director of the Language Center, Soochow University. 


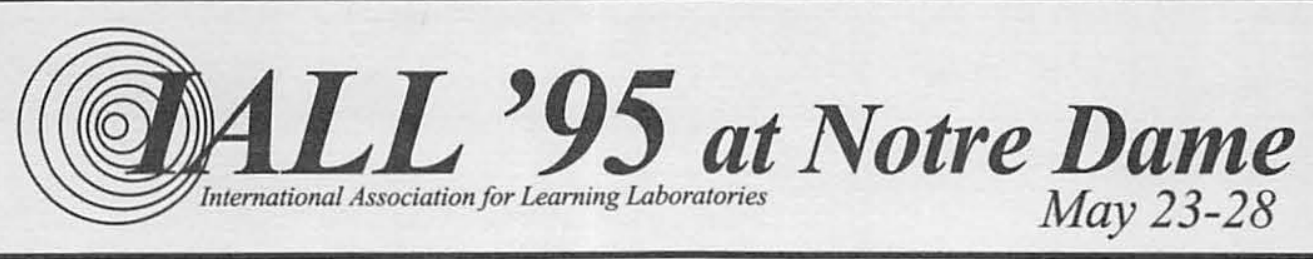

\section{Language Labs on the Leading Edge}

\section{Theme of the conference:}

Advancements in electronic technologies have placed many language labs at the forefront of the technological revolution in education. Computers, digital media, and satellite communications are now commonplace in many labs around the world. New labs and renovated labs often include many or all of these technologies, and at many institutions it is the lab directors who are the most knowledgeable about them. Often it is lab directors who are the keepers of technological memories; who, while constantly informing themselves of advancements, at the same time maintain an experience file of the good and the not-so-good of years past. The goal of IALL '95 at Notre Dame is to share that experience, provide information about the latest technologies along with an opportunity to develop familiarity with them, to provide opportunities for professional growth, and to continue to assess and evaluate the role of technology in the language learning process.

Founded in 1842, the University of Notre Dame has a rich traditional heritage. The campus, located on a scenic 1250 acres on the north side of South Bend, Indiana, is home to about 10,000 undergraduate and graduate students from all over the United States and some 72 foreign countries.

Right next to Knute Rockne football stadium is perhaps the most technologically advanced classroom building in the United States, DeBartolo Hall. Its 84 classrooms are all connected to Media-On-Call, a centralized media distribution network for images, sound and data. Over the Internet and via satellite, the world can be brought into meeting rooms that vary in size from 20 -seat seminar rooms to a 450 -seat auditorium. Uplink capability makes worldwide broadcast of some IALL '95 proceedings a possibility to consider. Make plans now to attend for sure, perhaps to present, at IALL '95 at Notre Dame. Put it on your calendar. Preconference workshops in video editing, computer applications, instructional design, lab design and management begin May 23 and 24; conference sessions begin May 25 and finish May 27 in the afternoon. Board and council meetings are scheduled on May 28. The call for proposals will appear in September 1994.

\section{IALL '95 at Notre Dame is for you if you are:}

* managing a language lab, learning lab, or media lab...

* interested in the role of the language lab...

* planning a new lab or renovating an old one...

* new to the profession..

* a teacher or researcher in language learning methodologies

* interested in the role of technology in teaching and learning...

Exhibits PLUS! IALL '95 at Notre Dame will feature:

* Language Lab Equipment, Hardware, Software

* Integrated courseware (textbooks and media)

\section{For more information:}

EMail:

IALL95@nd.edu
Voicemail:

(219) 631-4269

-leave address information
Perennial conference favorites:

* Teaching Languages with Technology: What's new?

* Language Labs Around the World

* Designing new labs and renovating older labs

* Managing people, resources and money

* Getting money: •budgets • grants

* Pre-conference workshops: •computer applications $\bullet$ video editing $\bullet$ multi-media $\bullet$ networks $\bullet$ and more

* Keeping it legal: copyright issues
Write to:

IALL ' 95 at Notre Dame

Center for Continuing Education P.O. Box 1008

Notre Dame, IN 46556-1008 